\title{
Typology in Vernacular Architecture-Qianmo Tower Post Station in Mingyue Village
}

\author{
Li Yunzhang ${ }^{1}$, Zhu Yuhong ${ }^{1}$, Yu Lirong ${ }^{2}$, Bi Zhongsong ${ }^{1,3}$, and Huang Guanjun ${ }^{3 *}$ \\ ${ }^{1}$ College of Architecture and Environment, Sichuan University,610000 Chengdu,China \\ ${ }^{2}$ College of Physical Education, Sichuan University,610065 Chengdu, China \\ 3 *College of Architectural and Engineering \& Research Center of Huizhou Architecture, Huangshan University,245041 Huangshan, \\ China
}

\begin{abstract}
The acceleration of the modernization process has promoted the improvement of rural residential construction technology and efficiency, but the rural buildings have not inherited and developed the regional traditional characteristics on this basis, instead, there has been a blind trend of urban architectural styles in different regions, resulting in a phenomenon of the homogenization of development. The design of qianmota post station uses the typological analysis method to excavate and inherit the characteristics of the local traditional buildings in Mingyue village, then combines the characteristics with new technologies and materials to restore the local architecture in the hearts of the villagers in Mingyue village. It is restored in two aspects: the architectural appearance of the traditional houses in Western Sichuan and the spiritual symbol of the church.
\end{abstract}

\section{Field crossroads, tall bamboo forest- the ancient Mingyue village.}

Mingyue village, an ancient village located in Ganxi Town, Pujiang County, Chengdu, 90 kilometers from downtown Chengdu, has been the resting post station on the Southern Silk Road and the Tea-horse Ancient Road since the Sui and Tang dynasty. The history of pottery production in the village is as long as that of tea. (Fig. 1) The best-preserved "Mingyue Kiln" in the village, whose firing process still retains the skills of the Tang Dynasty, is currently considered as the only "existing Qiong Kiln" in Sichuan province ${ }^{[1]}$. (Fig. 2) Here, the villagers work at sunrise and rest at sunset, and their pottery-making, tea-growing, and land-farming are passed from generation to generation; There is an ancient charm in this village: the old pine trees are beautiful, and the old kiln is rest in peace, and the elderly and children are living a happy and satisfying life.

However, like many other villages in China, Mingyue village, with the acceleration of urbanization, has also faced with a series of problems in terms of the destruction of the rural natural environment, the gradually disappearing traditional culture, the massive outflow of local population, and the constant loss of vitality in the village. Therefore, started with Mingyue Kiln, Mingyue village officially launched the Mingyue International Pottery village project in the year 2014, relying on its unique rural environment and cultural resources. While great concern has been put into developing ecological agriculture of phyllostachys praecox and tea, cultural and creative tourism projects and art facilities were also introduced to form its brand of Mingyue village "Cultural and Creative village". Relying on its unique development model, Mingyue village has now successfully got rid of the title of poor village in the past and became an icon for rural revitalization and rural development ${ }^{[2]}$.
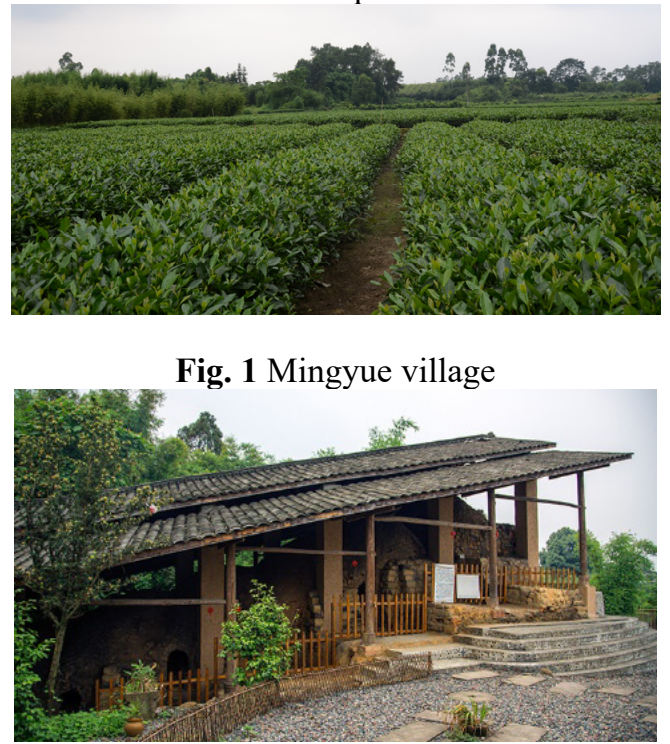

Fig. 2 The best-preserved "Mingyue Kiln" in the village

Although the change of business format has made Mingyue village a well-known celebrity online and this ancient village is once again vibrant. Local villagers are also losing the memories of the traditional farming life and their attachment to neighboring relationships.

* Corresponding author: 1445033373@qq.com 
Therefore, in the design of Qianmo Tower post station, the team hopes to extract and utilize the elements of different local vernacular architecture from the perspective of architectural typology - to restore the "archetype" of vernacular architecture in local residents' memory, thus creating a place that can carry homesickness and a place where the soul belongs.

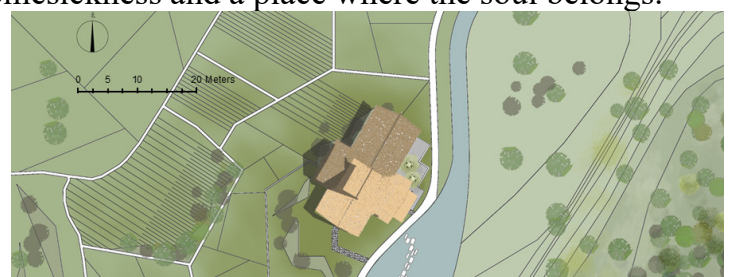

Fig. 3 General layout of Qianmo Tower

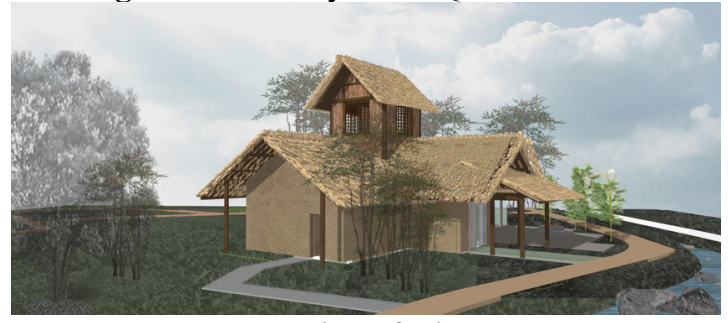

Fig. 4 Perspective of Qianmo Tower

\section{Architectural typology: extraction of archetypes of rural architecture in western Sichuan}

Architectural typology is an important and general way to analyze architecture. Typological theory would find certain types from a wide range of materials, then summarize and categorize the existing types as to graphically convert them into simple geometric figures, namely archetypes, and discovers its variants. Finally the design would be proceed based on common elements of archetypes and its variants. Typological theory tends to extract and find architectural images from collective memory and human archetypes in its design. By establishing architectural intentions, typological methods allow the reproduction of the conventional forms in people's memory, and provide a followable way fro the combination of this conventional form with modern design activities ${ }^{[3]}$.

Mingyue village has a long history and unique regional characteristics. This village is located in the depths of the Pujiang River. It is quiet and full of humanistic feelings. In such a comfortable environment, the collective memory of the villagers must carry a unique understanding of the local vernacular architecture archetype. Vernacular buildings, constructed by humans, have the universal value of being local characteristics and shaping the memories of villagers, thus are vividly expressed as a unique impression of a certain period. Furthermore, this image has become the most paramount concept in the field of vernacular architecture, given its interconnections with the local history and culture and the behaviour of local villagers ${ }^{[4]}$. Meanwhile, it carries specific spiritual values. Although the vernacular architecture in Mingyue village' $\mathrm{s}$ historical period is gone forever, as architects, we seek to discover the "archetype" form of vernacular architecture that exists in the memory of local residents and find eternal value from it, so as to generate new ideas

For this ancient village, what is the archetype of the local vernacular architecture?

Before designing the Qianmo Tower post station in Mingyue village, the design team went to Pujiang county for on-site investigations. Text materials and drawings were sorted out through visits and exchanges, on-site surveying and mapping, document collection and other methods. (Fig. 5,6) After typological analysis of the data, we summarized the current features of the local buildings in Mingyue village, and compared these features with the same types of buildings in the historical period, so as to sum up the universal archetype of Mingyue village's vernacular architecture. These preliminary surveying and drawing papers and the archetype research of Mingyue village's vernacular architecture have played a guiding role in the design process of Qianmo Tower post station.

The typological approach emphasizes the establishment of architectural intentions to restore conventional forms in people's collective memory ${ }^{[5]}$. The residential buildings in western Sichuan, represented by Mingyue village, are mostly through type timber frame, with sloped roofs and thin eaves, creating an environment that is open and transparent, light and delicate, elegant and simple. However, the external shape of the building alone is insufficient to establish the archetype of Mingyue village's vernacular architecture. Western Sichuan architectural culture is a highly compatible fusion culture, which has not lost its tradition while absorbing foreign cultures. Modern church buildings in Chengdu are a typical example.

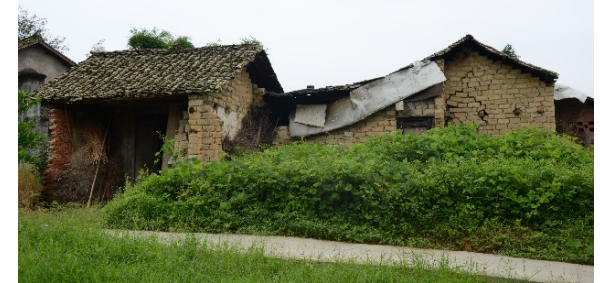

Fig. 5 The local buildings in Mingyue village

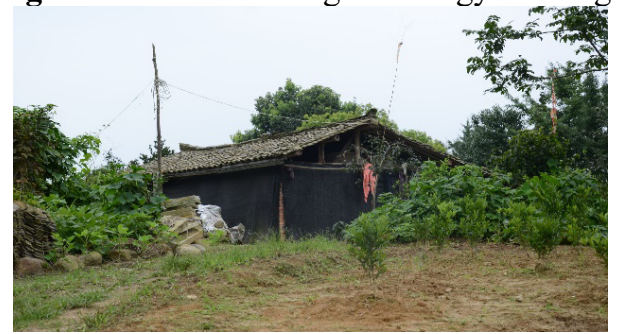

Fig. 6 The local buildings in Mingyue village

Therefore, in the design process, the team decided to maintain the traditional houses of Mingyue village in Western Sichuan, while drawing inspiration from church architecture to introduce this centralized and symbolic architectural type. And eventually, restore the vernacular architecture in the minds of the villagers in Mingyue village from the two aspects: the architectural appearance of the houses and the spiritual symbolization of churches. 


\section{Combination of Chinese and western architectural styles - The blending of Basilica and traditional western Sichuan residence}

"Sichuan Chronicles. Architecture Chronicles"[6] states that "the earliest modern building in Sichuan was the Catholic Church". The church architecture reflects the level of Chinese construction at that time, the spread of Western architectural art in Sichuan, and the development of local architectural art. During the early state when Catholicism was introduced into Sichuan, it could only be spread in the countryside far from the city in a low profile due to the influence of etiquette disputes, retreat policies, and Sichuan religious cases. Rural churches, therefore, shaped its unique form of combining Chinese and Western architectural styles under this background $^{[7]}$.

The design of Qianmo Tower post station follows the combination of Chinese and Western characteristics of rural churches in Western Sichuan. It adopts a Western Basilica layout, while the house structure adopts the traditional Western Sichuan architectural form, showing an ingenious integration of these two cultures.

(Fig. 7,8)

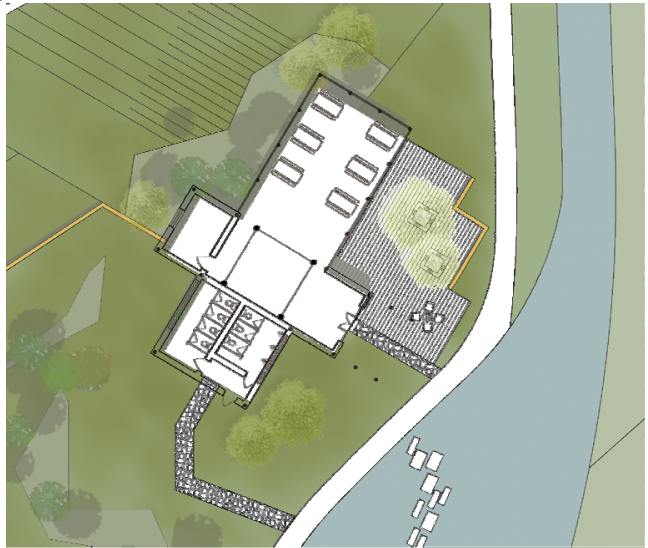

Fig. 7 First floor plan of Qianmo Tower

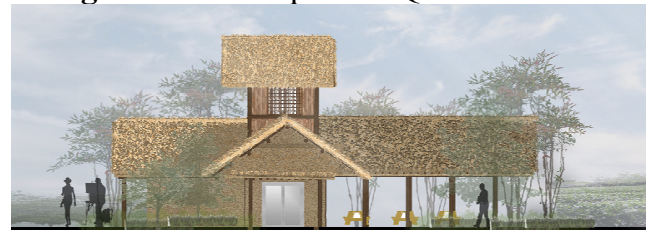

Fig. 8 Elevation of Qianmo Tower

The plane composition of the building is inspired by Western churches, using a typical Basilica layout. The longitudinal hall of the post station is rectangular, and the lateral halls are added to the ear rooms on both sides, which are cross-shaped as a whole. There are four columns of pillars inside the longitudinal hall, which divide the hall into three long spaces. The central one is wider, which is the central hall, and the sides are slightly narrower, which are side corridors. Although the design simplifies the two columns in the middle, the Basilica style representing the form of the central hall higher than the side corridors is still retained - the tower structure in the center. However, in terms of the facade structure, Qianmo Tower post station retained as much as possible the characteristics of western Sichuan residential houses, and redefined the component materials of the facade according to the modern functional requirements and the element in through type timber frame of western Sichuan residential buildings. The facade of the steel frame structure not only follows the graphic elements of the through type timber frame in Western Sichuan, but also incorporates the stained glass window elements of Western churches. Between light and shadow, the colors are colorful and mottled, as if a world away. ( Fig. $9,10)$

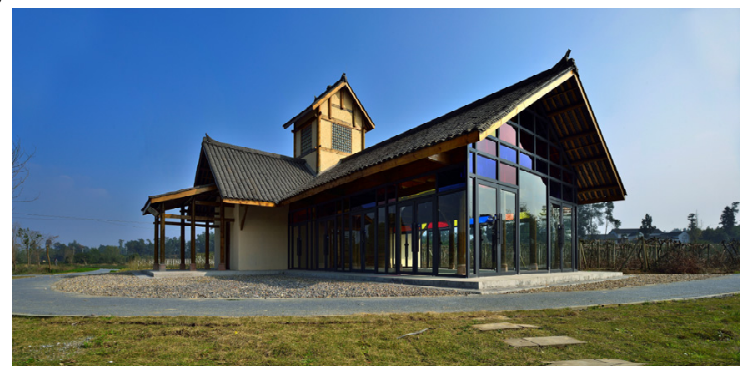

Fig. 9 The stained glass window of Qianmo tower

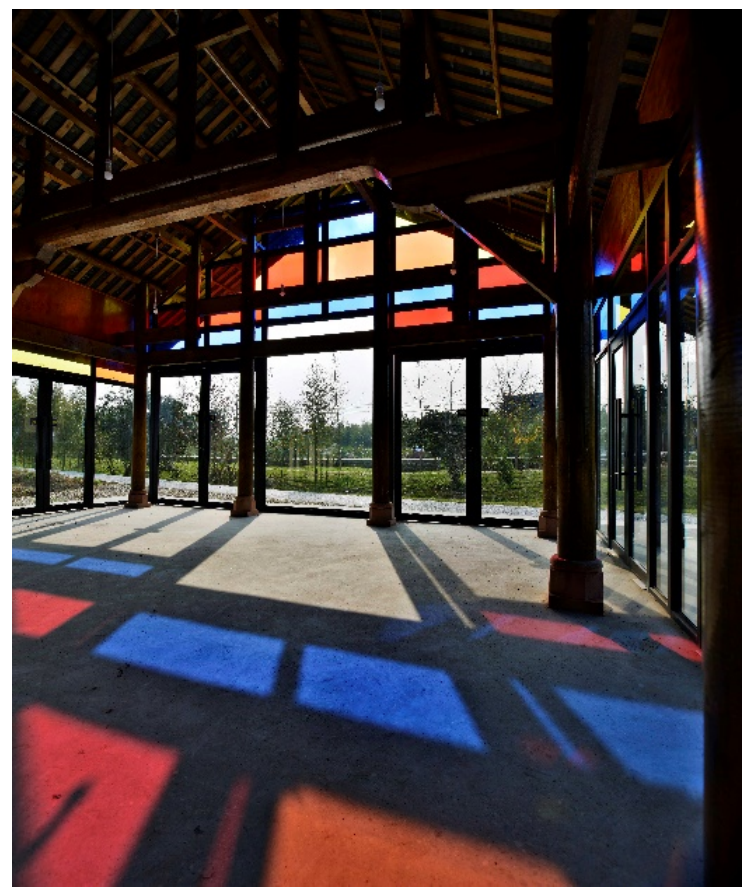

Fig. 10 The stained glass window of Qianmo tower

The bell tower in the centre of the post station takes the towering structure of the Basilica-style central hall as the starting point and combines the intention of "tower" to shape the composition centre and spiritual fortress of the post station. The exterior of the bell tower follows the through type timber frame of the western Sichuan residential houses. (Fig. 11) The roof of the green tile slope, the eaves are thin, forming a light architecture style; the wooden pillars are cylindrical, surrounding the building, slender and stable; the walls are built with soil, natural and simple; the walls are decorated with wooden square windows, enriching the structure of the facade.

The external sense of form could affect psychological activities of human. The tall, straight, and 
pointed structure of the bell tower shows a strong upward momentum. Such a structure is often easy to become the focus of people's vision. The utilization of the through type timber frame in western Sichuan and local materials in the post station make this place full of historical vicissitudes and human warmth. (Fig. 12) As time goes by, the bell tower will be repeatedly used by local residents as an identifying structure of the station; And as residents become more familiar with Qianmo Tower Station, their reliance on the bell tower would increase accordingly. Finally, the bell tower is likely to become a landmark in the site, and then gradually merge into the memory of local residents.

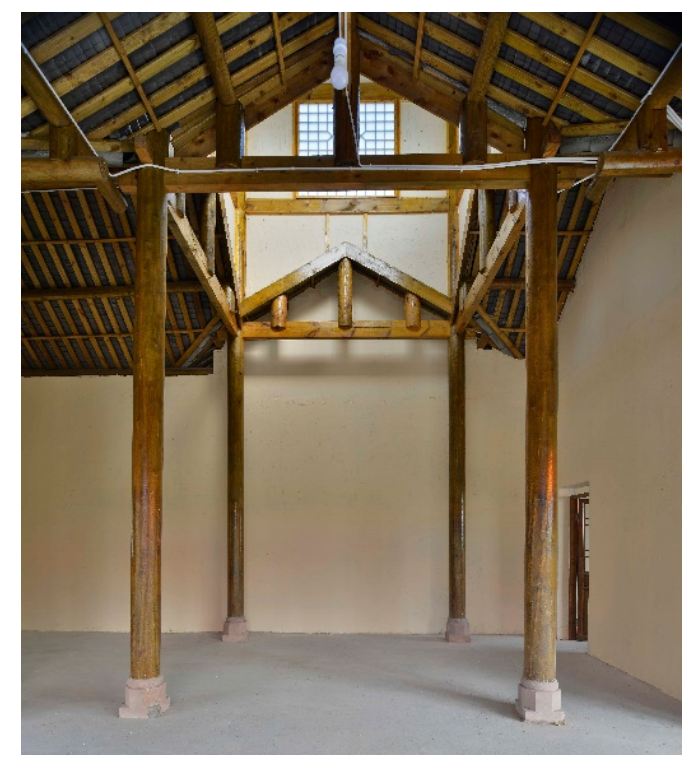

Fig. 11 The bell tower

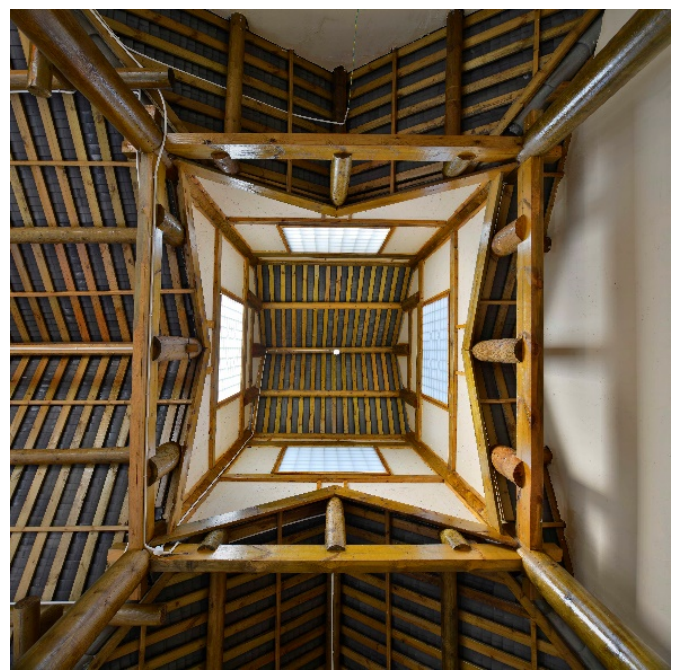

Fig. 12 Interior structure of the bell tower of Qianmo Tower

\section{Attach importance to nature and return to the native land-attention and response to the local natural environment}

Paying attention to and responding to specific natural environments is one of the key characteristics of vernacular architecture ${ }^{[8]}$. Architecture does not exist in isolation, it always be in a certain environment. Therefore, issues such as " how the building combines the original environment? ", " How to use the intangible factors such as local climate conditions? " , And "what posture the building itself appears in the tangible environment? " are aspects that must be considered in architectural creation. In the design process, Qianmo Tower Station especially focus on combining the external appearance of the building with the local environment of Mingyue village, giving people an overall image, and at the meantime, enabling people to feel the external nature while inside the building. This would also deepen people's experience and impression of the local characteristics and natural environment of Mingyue village and create a sense of belonging.

Pine forests, tea valleys, and rice fields slowly stretch out along the texture of the hills of western Sichuan, and the unique residential houses of western Sichuan are scattered among them - the simple and comfortable natural environment of Mingyue village. The design of Qianmo Tower Station is based on the concept of local houses and rural churches in western Sichuan. It absorbs the Basilica-style plane composition of the Catholic Church and uses the structure and materials of the houses in western Sichuan. Meanwhile, it is dominated by natural landscapes and is coordinated with the surrounding environment, including the use of overall colors, the use of topography, the combination with the terrain and the reflection of the stream, etc. These allow the station as compatible as possible with the surrounding environment without sacrificing the centrality and symbolism of the building. (Fig. 13)

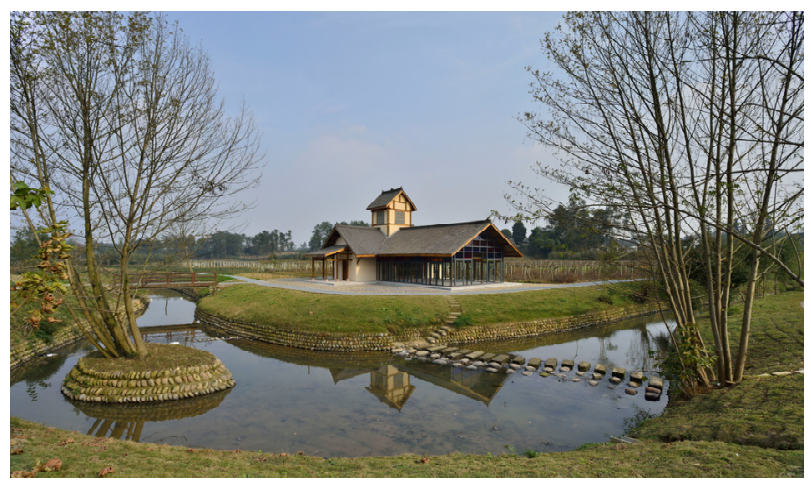

Fig. 13 External environment of Qianmo Tower

\section{Vernacular architecture and its future development}

Vernacular architecture is a materialized product of the development of rural culture under a specific natural and social context. In the process of evolution, the rural 
buildings have condensed unique regional characteristics, some of their characteristics have been preserved, while others have gradually disappeared in the evolution. " How to generalize and abstract the archetype of the rural architecture? ", " How to give the beauty displayed in it an eternal charm? ", And " how to create a building that enhances historical significance and meets the needs of modern development? ". Those are issues those run through the design process of Qianmo Tower Station.

With the acceleration of the modernization process and the implementation of the country's policy of socialism new rural reconstruction, the construction technology, construction materials and construction efficiency of rural dwellings have been noticeably promoted. However, the buildings in the countryside have not inherited and developed the traditional characteristics of the region on this basis. Instead, there has been a phenomenon of homogenization development caused by the blind tendency of different regions to urban architectural styles. Local architecture is also accelerating its loss of the unique regionality in this process. As a rational analysis method, typology simultaneously constructs buildings and cities, connects tradition with the present, and integrates architecture and nature. It helps to excavate and inherit the characteristics of local traditional architecture, and to use new technologies to combine it with materials.

In Qianmo Tower, the original architectural form of the western Sichuan residential houses retains the architectural archetype of the western Sichuan residential houses, and retains the original outlook of the hometown architecture existed in the memories of local residents; the Latin cross Basilica-like plane layout of the western church also attaches the construction with religious iconicity and centrality. The QianMo Tower combines the types of traditional houses in Western Sichuan and the Basilica style of Latin cross, adding a cohesive force to the local architecture in the hearts of residents.

Strolling in the QianMo Tower to feel the combination of Chinese and western culture, the overlap of tradition and modernity, and the blend of homesickness and foreign places. It is like a doublesided mirror, illuminating the past and the future of this land.

\section{Acknowledgment}

This paper has been supported by the following fund projects. MOE (Ministry of Education of the People's Republic of China) Youth Fund Project of Humanities and Social Sciences (Project No.18YJC850002). Bidding Project of Key Research Base of Humanities and Social Sciences in Colleges and Universities of Anhui Province (Project No. SK2015A170).

\section{References}

1. Gao Xin. Analysis on the role of cultural and creative industries in rural community construction - Taking Mingyue village in Pujiang County as an example [J]. China market, 2019 (17): 25-26

2. Guan Xiuyuan. Feasibility analysis on the development of rural tourism driven by cultural and creative industries: a case study of Mingyue village, Ganxi Town, Pujiang County [J]. Anhui agronomy bulletin, 2019, 25 (01): 22-23

3. Urban architecture [M]. China Architecture press, (Italy) Rossi, 2006

4. Zhao Xing. Contemporary "construction" road of traditional vernacular architecture [D]. Tianjin University, 2005

5. Tian Rongrong. Research on the practice of new vernacular architecture in Southwest China from the perspective of construction [D]. Guizhou University, 2018

6. Sichuan local chronicle Compilation Committee. Sichuan Provincial annals · architectural records [M]. Chengdu: Sichuan Science and Technology Press, 1996

7. Cao Lun. Modern Catholic Church Architecture in Western Sichuan [D]. Southwest Jiaotong University, 2003

8. Zhu Jinliang. Research on the creative practice of contemporary Chinese Vernacular Architecture [D]. Tongji University, 2006

9. Zhang Jizhen. Applied research on Typology in the renewal and development of rural settlements in western Henan [D]. Hunan University, 2010. Li Bin. Analysis of inheritance and revival of local architectural culture [D]. Tianjin University, 2018

10. $\mathrm{Wu}$ Liangyong. Modernization of vernacular architecture and regionalization of modern architecture: on the way to explore new architecture in China [J]. Central China architecture, 1998 (01): 3-5

11. Wu Zhihong. Context, problems and prospects of Chinese vernacular architecture research [J]. Journal of Kunming University of science and Technology (SOCIAL SCIENCE EDITION), 2014,14 (01): 103108

12. Han Dongqing. Types and vernacular architectural environment -- on the environmental understanding of villages in southern Anhui [J]. Acta architecturae, 1993 (08): 52-55 